\title{
(RE)CONSTRUÇÃO DAS CONCEÇÕES CTS DE FUTUROS PROFESSORES DE CIÊNCIAS*
}

\author{
(Re)construction of STS conceptions for future Science teachers
}

(Re)construcción de concepciones CTS para futuras profesores de Ciencias

\begin{abstract}
Mónica Seabra*
Rui Marques Vieira*

Resumo

Na educação em Ciências, partir das conceções Ciência-Tecnologia-Sociedade (CTS) dos futuros professores (FP), poderá permitir a conceptualização e a redefinição de cursos de formação inicial de professores (FIP) mais eficazes. Este estudo teve como finalidade averiguar a (re)construção das conceções CTS de três FP do $1 .^{\circ}$ e do $2 .^{\circ}$ Ciclos do Ensino Básico, ocorrida no âmbito da formação em Didática das Ciências Naturais. Esta intervenção contemplou o desenvolvimento de atividades de cariz CTS formais e de saída de campo. Para a recolha de dados, foi aplicado o questionário Views-On-Science-Technology-Society -VOSTS e foram realizadas entrevistas individuais semiestruturadas. Este estudo assumiu uma natureza qualitativa, tendo sido a análise de conteúdo a técnica privilegiada no tratamento dos dados recolhidos. Verificou-se que no início da formação em Didática das Ciências predominava um desconhecimento das complexas interações CTS e que após a mesma os estudantes mostraram uma imagem mais contextualizada da Ciência. Concluiu-se, portanto, que além de se apresentarem e discutirem práticas CTS é preciso adotá-las na FIP (de Ciências), uma vez que estas parecem contribuir para que os FP ultrapassem conceções de Ciência desadequadas e à margem das suas inter-relações com a Tecnologia e a Sociedade.
\end{abstract}

PALAVRAS-CHAVE: Formação inicial de professores. Conceções. Educação CTS, Contextos de Ciência e Tecnologia

\begin{abstract}
In Science Education, starting from future teachers' (FT) Science-Technology-Society (STS) views may enable the conceptualization and redefinition of more effective initial teacher education programs (ITEP). This study, aimed to investigate the (re)construction of the STS views of three elementary school FT, in the framework of an intervention in the Curricular Unit (CU) of Didactics of Natural Sciences. This intervention included the development of formal and field trip STS activities. For data collection, the questionnaire Views-On-Science-Technology-Society - VOSTS (abbreviated version of 19 items, by Canavarro, 2000) was applied, and semi-structured individual interviews were carried out. This study assumed a qualitative nature, and content analysis was the preferred technique for the treatment of collected data. The use of this technique made it possible to examine that, at the beginning of the $\mathrm{CU}$ there was a predominance of a lack of knowledge about

* Este trabalho enquadra-se no projeto de investigação de doutoramento com a referência SFHR/BD/121350/2016 e é financiado por Fundos Nacionais através da FCT - Fundação para a Ciência e a Tecnologia, I.P., no âmbito do projeto UID/CED/00194/2019.

* Doutoranda com Bolsa de Investigação da Fundação para a Ciência e Tecnologia (FCT), Centro de Investigação em Didática e Tecnologia na Formação de Formadores - CIDTFF, Universidade de Aveiro, 3810-193 Aveiro, Portugal. E-mail: monicaseabra@ua.pt.

* Doutor em Didática pela Universidade de Aveiro (UA-PT). Prof. Doutor Auxiliar C/ Agregação, CIDTFF, Universidade de Aveiro, 3810-193, Portugal. E-mail: rvieira@ua.pt.
\end{abstract}


the complex STS interactions and that after the intervention the evolution towards a more contextualized image of Science was evident. It was concluded that besides presenting and discussing STS practices it is necessary to adopt them in ITEP (of Sciences), since these seems to contribute to FT to overcome unsuitable views of Science and to the margin of their interrelations with Technology and Society.

KEYWORDS: Initial Teacher Training. Views. STS Education. Science and Technology Contexts

\section{Resumen}

En la educación en Ciencias, partir de las concepciones Ciencia-Tecnología-Sociedad (CTS) de los futuros profesores (FP) podrá permitir la conceptualización e redefinición de cursos de formación inicial de profesorado (FIP) más eficaces. Este estudio, tuvo como finalidad averiguar la (re)construcción de las concepciones CTS de tres FP de Educación Primaria, ocurrido en el marco de una intervención en la asignatura de Didáctica de las Ciencias Naturales. Esta intervención contempló el desarrollo de actividades CTS formales y de salidas de campo. Para la recogida de datos se aplicó el cuestionario Views-On-Science-Tecnology-Society - VOSTS (versión abreviada de 19 elementos de Canavarro, 2000) y realizadas entrevistas individuales semi-estructuradas. Este estudio asumió una naturaleza cualitativa, habiendo sido el análisis de contenido la técnica privilegiada en el tratamiento de los datos recogidos. Por medio de estos, se constató que al inicio de la UC prevalecía un desconocimiento de las complejas interacciones CTS y que tras la intervención los estudiantes mostraran una imagen más contextualizada de la Ciencia. Se concluyó que además de presentarse y debatir prácticas CTS es preciso adoptarlas en la FIP, ya que estas parecen contribuir para que los FP sobrepasen concepciones de Ciencia inadecuadas y al margen de sus interrelaciones con la tecnología y la sociedad.

PALABRAS CLAVE: Formación inicial de profesores. Concepciones. Educación CTS. Contextos de Ciencia y Tecnología

\section{INTRODUÇÃO}

Os desafios que se colocam à Educação, perante uma sociedade em constante mudança, implicam que a escola se ajuste ao que o mundo precisa, preparando os jovens em função dos novos cenários desconhecidos, incertos e imprevisíveis (NÓVOA, 2011). Neste contexto, importa que os sistemas educativos contribuam "para o desenvolvimento de valores e de competências nos alunos que lhes permitam responder aos desafios complexos deste século e fazer face às imprevisibilidades resultantes da evolução do conhecimento e da tecnologia" (MINISTÉRIO DA EDUCAÇÃO [ME], 2017, p. 7). Contudo, as práticas didático-pedagógicas dos professores, caracterizadas por perspetivas convencionais, empiristas e indutivistas, continuam a persistir à escala nacional e internacional (VIEIRA; TENREIRO-VIEIRA; MARTINS, 2011). Defendendo-se uma Educação em Ciências com orientação Ciência-Tecnologia-Sociedade (CTS) e considerando que o professor é uma das peças chave para efetivar a mudança educacional necessária, é fundamental que a sua formação se baseie numa filosofia sócio-construtivista da Ciência, o que implica uma prévia caracterização das suas conceções sobre as interrelações CTS (DIKMENTEPE; YAKAR, 2016; VIEIRA; MARTINS, 2005).

Neste contexto, o estudo que se apresenta, correspondente a parte de uma investigação (em curso) mais ampla, teve como finalidade averiguar a (re)construção das conceções sobre CTS de três futuras professoras, ocorrida no âmbito de uma intervenção 
na Unidade Curricular (UC) de Didática das Ciências Naturais do Mestrado em Ensino do 1. ${ }^{\circ}$ Ciclo do Ensino Básico (CEB) e de Matemática e Ciências Naturais no 2. ${ }^{\circ} \mathrm{CEB}$.

Explana-se, neste artigo, uma síntese da fundamentação teórica que sustentou o estudo; faz-se também referência à sua metodologia; apresentam-se e discutem-se os resultados e as conclusões e implicações que os sustentam.

\section{Contextualização teórica}

Atualmente, é indiscutível o papel que a Ciência e a Tecnologia representa na sociedade contemporânea. Os desafios que se colocam aos cidadãos do século XXI são diferentes daqueles do século anterior e várias questões anteriormente desconhecidas tornaram-se, agora, prioritárias (DE PRO BUENO, 2017), como: sustentabilidade, hábitos saudáveis, alterações climáticas, aquecimento global, reprodução medicamente assistida, novas tecnologias da informação e comunicação. É, portanto, fundamental almejar uma Educação em Ciências para todos, desde os primeiros anos de escolaridade, numa perspetiva de promoção da alfabetização científica, capaz de formar cidadãos com competências para agir de forma responsável, informada e fundamentada em situações que envolvem também dimensões tecnocientíficas (AIKENHEAD, 2009).

Nesta conjuntura, documentos políticos emergentes em todo o mundo (EURYDICE, 2012; NATIONAL RESEARCH COUNCIL, 2009; NATIONAL SCIENCE BOARD, 2014) recomendam uma Educação em Ciências cariz CTS, para um ensino contextualizado, que confronte os alunos com práticas didático-pedagógicas que valorizam as complexas interações CTS, contribuindo, assim, para melhorar os índices de alfabetização científica (VIEIRA; TENREIRO-VIEIRA, 2015). A educação em Ciências pautada pela perspetiva CTS, "advoga a (re)construção de conhecimentos científicos e o desenvolvimento de atitudes e de capacidades de pensamento, incluindo de pensamento crítico, no contexto da abordagem de assuntos e da resolução de problemas sociais que envolvem a Ciência e a Tecnologia" (TENREIRO-VIEIRA; VIEIRA, 2016, p. 146). Contudo, apesar do reconhecimento contínuo dos benefícios da Educação CTS, vários estudos (e.g., MANSOUR, 2013; RIGA et al., 2017; VIEIRA; TENREIRO-VIEIRA; MARTINS, 2011) têm convergido no diagnóstico de práticas caracterizadas por perspetivas convencionais, empiristas e indutivistas, o que poderia ser explicado pela incompatibilidade entre as conceções dos professores e os objetivos da Educação CTS (AMIRSHOKOOHI, 2010).

As investigações sobre a influência das conceções dos professores nas suas práticas didático-pedagógicas e, consequentemente, nas conceções dos seus alunos são paradoxais. De facto, enquanto alguns autores (e.g., ANDERSON, 2015; WILKINS, 2008) sustentam a ideia de que as conceções dos professores têm influência nas suas práticas de sala de aula e, consequentemente, nas conceções dos seus alunos, outros, como Buehl; Beck (2015) e Mansour (2013), defendem que o facto de as conceções manifestadas pelos professores irem ao encontro do que social e profissionalmente é aceitável não significa, necessariamente, a transferência para a prática. Em todo o caso, estas relações entre as conceções dos professores, as suas práticas e as conceções dos alunos, no contexto de uma visão inadequada acerca da natureza da Ciência e das suas interligações com a Tecnologia e a Sociedade, podem originar uma atitude negativa face à Ciência e ao desinteresse dos alunos pela sua aprendizagem (AMIRSHOKOOHI, 2010). Assim, conhecer as conceções 
CTS dos professores são aspetos essenciais na efetivação de uma Educação em Ciências promotora da alfabetização científica dos seus alunos.

Os professores, em diversos estudos efetuados sobre as suas conceções, têm evidenciado que possuem imagens da natureza da Ciência afastadas do que atualmente é advogado em visões consentâneas com o empreendimento científico contemporâneo (PRO BUENO, 2003). Também nas investigações levadas a cabo com futuros professores de Ciências têm sido conhecidas conceções CTS ingénuas, como as que Amirshokoohi (2010), Dikmentepe; Yakar (2016) e Yalvac et al. (2007) destacam: (i) a Ciência é vista como uma acumulação de factos, fenómenos, leis e teorias de carácter universal; (ii) a Ciência e a Tecnologia são essencialmente encaradas como um empreendimento único (tecnociência); (iii) a Tecnologia, associada a artefactos materiais e equipamentos, é vista como a aplicação da Ciência, surgindo, portanto num patamar hierarquicamente inferior; (vi) a valorização excessiva, numa ótica tecnocrática, dos pareceres dos especialistas nos momentos de tomada de decisões relevantes sobre consequências sociais da Tecnologia; (v) a investigação científica é encarada como meio de desvendar verdades definitivas e absolutas; (vi) os cientistas são vistos como pessoas rigorosas, socialmente isoladas, despidas de interesses e motivos pessoais e (vii) a Ciência e a Tecnologia são encaradas como progresso económico e, por isso, progresso social.

São diversas as razões que têm sido apontadas para o facto de os professores evidenciarem conceções inadequadas acerca da natureza da Ciência, por confrontação com conceções contemporâneas do empreendimento científico, nomeadamente o seu próprio percurso de formação anterior, muitas vezes próximo de uma abordagem transmissiva, e os meios de comunicação social (RIVERO et al., 2017).

Esta realidade não deve ser ignorada na formação inicial de professores, uma vez que esta servirá de modelo para as conceções e práticas didático-pedagógicas dos futuros professores (ANDERSON; MOEED, 2017; RODRIGUES; MARTINS, 2018). Assim, para que os futuros professores possam atender às recomendações internacionais para melhorar o ensino das Ciências - e se este está (em maior ou menor grau) relacionado com as conceções CTS dos mesmos, é fundamental o papel e a formação dos professores. É, portanto, crucial, no quadro de uma Educação em Ciências que valoriza a perspetiva CTS, conhecer as conceções dos futuros professores a este respeito, compreendendo o que pensam e identificando conceções inadequadas. Assim, partir das conceções de futuros professores sobre Ciência, numa perspetiva de interligação com a Tecnologia e a Sociedade, poderá permitir a conceptualização e a redefinição de cursos de formação inicial de professores mais eficazes (VIEIRA; MARTINS, 2005).

Diante do exposto, no caso particular de professores do Ensino Básico em formação inicial, ressalta a escassez de estudos e a quase inexistência de intervenções específicas que possibilitem aos futuros professores (re)construírem as suas conceções CTS. Este estudo resulta, portanto, de um esforço para começar a suprir esta lacuna na literatura.

\section{Metodologia}

O presente estudo teve como finalidade averiguar a (re)construção das conceções sobre CTS de três futuras professoras, ocorrida no âmbito de uma intervenção na Unidade Curricular (UC) de Didática das Ciências Naturais (DCN) do Mestrado em ensino do 1. ${ }^{\circ}$ 
CEB (alunos de 6 a 9 anos) e de Matemática e Ciências Naturais no 2. ${ }^{\circ}$ CEB (alunos de 10 a 12 anos), de uma instituição de ensino superior universitário portuguesa.

A referida intervenção contemplou o desenvolvimento de atividades de cariz CTS, nomeadamente atividades formais e uma saída de campo a um contexto real de Ciência e Tecnologia (laboratório de Microbiologia de uma Universidade Portuguesa). A realização das atividades de cariz CTS tiveram como referência: (i) o Perfil do Aluno à Saída da Escolaridade Obrigatória - PA (Ministério da Educação [ME], 2017), documento de referência para a organização de todo o sistema educativo português que define as áreas de competências que se pretende que os/as alunos/as alcancem no final do $12 .^{\circ}$ ano de escolaridade e (ii) as Aprendizagens Essenciais de Ciências Naturais referentes ao $2 .^{\circ}$ Ciclo do Ensino Básico (ME, 2018), referencial curricular que visa promover o desenvolvimento das áreas de competências inscritas no PA.

Descrevem-se, de seguida, as atividades de cariz CTS desenvolvidas, assim como as técnicas, os instrumentos de recolha, a forma de análise de dados e a natureza do estudo.

\section{Atividades de Cariz CTS}

As atividades desenvolvidas no âmbito da UC de DCN, quer em contexto formal, isto é em sala de aula, quer em contexto de saída de campo, procuraram explorar explicitamente as inter-relações CTS.

Foram desenvolvidas, em contexto sala de aula, um conjunto de atividades, destacando-se aqui três: (i) o questionário de vinte e oito imagens de Jarvies; Rennie (2000); (ii) o set de oito fotografias de Jarvies; Rennie (2000) e (iii) a controvérsia sociocientífica sobre o uso de animais na investigação médica. O questionário de imagens, com vinte e oito desenhos, foi entregue às futuras professoras para que estas, individualmente, categorizassem cada um como relacionado com a Ciência, com a Tecnologia ou com nenhuma das duas. De seguida, cada futura professora partilhou a categorização que fez e criou-se uma discussão por forma a desconstruir algumas perceções, manifestadas pelas futuras professoras, sobre Ciência e Tecnologia.

$\mathrm{Na}$ segunda atividade formal, foram mostradas, às futuras professoras, oito fotografias (do set de imagens de JARVIES; RENNIE, 2000) de cientistas e tecnólogos(as) nos seus locais de trabalho. Nestas fotografias, é possível identificar: (i) apenas homens ou apenas mulheres a trabalhar em laboratórios; (ii) situações ou locais "não estereotipados" com apenas homens, apenas mulheres, pessoas com deficiência e pessoas com diferentes culturas; (iii) homens e mulheres cuja atividade não é especificamente identificável; (iv) homens e mulheres com uniformes que permitem distinguir a sua ocupação e (v) homens e mulheres cuja atividade é especificamente representada. À medida que se iam mostrando as fotografias, solicitou-se às futuras professoras que identificassem e justificassem se as pessoas que surgiam nas imagens eram cientistas ou tecnólogos. Em simultâneo, criou-se uma discussão para que as futuras professoras debatessem entre si as suas posições justificando-as. Por fim, mostraram-se novamente as oito fotografias por forma a desconstruir algumas conceções estereotipadas relativamente aos cientistas e a (re)construir perceções relativamente aos tecnólogos.

A controvérsia socio-científica implicou que as futuras professoras fizessem uma pesquisa, através de diversas fontes de informação, com o objetivo de procurarem razões a favor e contra o uso de animais na investigação médica. Estas razões, a favor e contra, 
foram posteriormente registadas numa tabela, facultada aquando do momento da pesquisa. Posteriormente, as futuras professoras tiveram que registar, noutra tabela, o peso em termos de importância das suas razões a favor e contra, registadas anteriormente. Por fim, foram confrontadas com a questão "Deve ser permitido o uso de animais na investigação médica?", que devia ser respondida por escrito de forma fundamentada e tendo em atenção as seguintes solicitações: "razões que apoiam a minha posição", "o que o meu interlocutor me pode dizer para me convencer a mudar de posição", "o que lhe posso responder" e "em resumo o que penso é".

A saída de campo consistiu na participação em um contexto real de Ciência e Tecnologia, nomeadamente ao MicroLAB (laboratório de Microbiologia da Universidade de Aveiro). A opção por este contexto real de Ciência e Tecnologia prendeu-se, sobretudo, com o facto de ser um laboratório dedicado ao estudo dos microorganismos que é uma das temáticas previstas nas Aprendizagens Essenciais da disciplina de Ciências Naturais do 5. ${ }^{\circ}$ ano de escolaridade (alunos de 9 anos). A visita, de aproximadamente duas horas, foi planeada pela investigadora, primeira autora deste artigo, juntamente com o responsável científico do laboratório, e dinamizada por este pesquisador, que começou por apresentar as diferentes valências físicas que compõem o MicroLAB, nomeadamente a sala de lavagem e esterilização dos microorganismos (onde se encontra uma autoclave) e os laboratórios dedicados à investigação da resistência a bactérias e à biologia dos fungos. Neste último, onde decorreu grande parte da visita, as futuras professoras tiveram a oportunidade de conhecer e visualizar de que modo é feita a investigação: (i) como se armazenam os microorganismos (observação da câmara frigorífica onde se congelam as amostras utilizando azoto); (ii) de que forma é feita a extração e a amplificação do DNA para a identificação dos fungos (visualização de diferentes micropipetas para a extração, do termociclador para a ampliação e do equipamento de eletroforese utilizado para estimar o tamanho dos fragmentos do DNA); (iii) como é realizada a descrição de novas espécies (sequenciação parcial do genoma e comparação com as bases de dados mundiais) e (iv) de que modo é feita a observação de fungos (apresentação do miscrocópio eletrónico de varrimento, seu respetivo funcionamento e visualização de algumas fotografias de fungos tiradas a partir do referido microscópio). No laboratório dedicado ao estudo da resistência a bactérias e à biologia dos fungos, foi também feita uma breve apresentação, pela pesquisadora responsável, da investigação que é desenvolvida e que se prende, particularmente, com a resistência a antibióticos em bactérias, não só hospitalares, mas também a nível ambiental (as futuras professoras visualizaram caixas de petri com amostras de antibiogramas) e com a avaliação de microbiomas de animais.

Importa ainda salientar que, no decorrer desta visita, as futuras professoras contactaram com outros investigadores que estavam nos laboratórios e que apresentaram brevemente a investigação que desenvolviam. A título de exemplo, um dos investigadores, ao desenvolver investigação relacionada com a resistência a antibióticos a nível ambiental, mostrou caixas de petri com culturas de fungos recolhidos no mar da região de Aveiro, Portugal.

Ainda nesta visita, o cientista, que a dinamizou, foi referindo diversas aplicações da investigação que desenvolvem no quotidiano. Revelou, por exemplo, que o MicroLAB colabora com hospitais para tratar doentes respiratórios, através da recolha de amostras para posterior identificação do fungo em laboratório. Além disso, o pesquisador confidenciou que as futuras professoras poderiam, facilmente, fazer um meio de cultura com os seus futuros alunos, utilizando flocos de aveia fervidos e filtrados. 


\section{Recolha e análise de dados}

Para avaliar o impacte da intervenção na (re)construção das conceções CTS das futuras professoras, recorreu-se à técnica de inquérito, através da aplicação de um questionário de escolha múltipla e da realização de entrevistas individuais semiestruturadas, no início e no final da intervenção. No primeiro caso, utilizou-se o "Views-On-Science-Technology-Society" (VOSTS) de Aikenhead, Ryan; Fleming (1989), na sua versão abreviada e previamente adaptada e validada para Portugal por Canavarro (2000). Esta versão portuguesa do VOSTS possui 19 itens, enquadrados em quatro dimensões, que permitem avaliar os tópicos apresentados no Quadro 1.

Quadro 1 - Dimensões, itens (com referência aos códigos originais) e respetivos tópicos da versão portuguesa do VOSTS

\begin{tabular}{|c|c|c|c|}
\hline Dimensões & Item & Código Original & Tópico \\
\hline \multirow{3}{*}{$\begin{array}{l}\text { Ciência e } \\
\text { Tecnologia }\end{array}$} & 1 & 10111 & Definição de Ciência \\
\hline & 2 & 10211 & Definição de Tecnologia \\
\hline & 3 & 10421 & Ciência e Tecnologia e qualidade de vida \\
\hline \multirow{3}{*}{$\begin{array}{l}\text { Influência da } \\
\text { sociedade na } \\
\text { Ciência e na } \\
\text { Tecnologia }\end{array}$} & 4 e 5 & 20121 e 20141 & Controlo político e governamental da Ciência \\
\hline & 6 & 20211 & Controlo da Ciência pelo setor privado \\
\hline & 7 & 20611 & $\begin{array}{l}\text { Influência de grupos de interesse particular sobre a } \\
\text { Ciência }\end{array}$ \\
\hline \multirow{5}{*}{$\begin{array}{l}\text { Influência da } \\
\text { Ciência e da } \\
\text { Tecnologia na } \\
\text { Sociedade }\end{array}$} & 8 & 40217 & $\begin{array}{l}\text { Contribuição da Ciência e da Tecnologia para } \\
\text { decisões sociais }\end{array}$ \\
\hline & 9 & 40311 & \multirow{2}{*}{$\begin{array}{l}\text { Contribuição da Ciência e da Tecnologia para a } \\
\text { criação de problemas sociais e investimento em } \\
\text { Ciência e Tecnologia versus investimento social }\end{array}$} \\
\hline & 10 & 40321 & \\
\hline & 11 & 40411 & $\begin{array}{l}\text { Contribuição da Ciência e da Tecnologia para a } \\
\text { resolução de problemas sociais }\end{array}$ \\
\hline & 12 & 40531 & $\begin{array}{l}\text { Contribuição da Ciência e da Tecnologia para o } \\
\text { bem-estar económico }\end{array}$ \\
\hline \multirow{3}{*}{$\begin{array}{l}\text { Características dos } \\
\text { cientistas }\end{array}$} & 13 & 60311 & Ideologias e crenças religiosas dos cientistas \\
\hline & 14 & 60411 & Vida social dos cientistas \\
\hline & 15 & 60611 & "Efeito do género" nas carreiras científicas \\
\hline $\begin{array}{l}\text { Construção social } \\
\text { do conhecimento } \\
\text { científico }\end{array}$ & 16 & 70212 & Tomada de decisão sobre questões científicas \\
\hline \multirow{2}{*}{$\begin{array}{l}\text { Construção social } \\
\text { do conhecimento } \\
\text { tecnológico }\end{array}$} & 17 & 80111 & Tomada de decisão sobre questões tecnológicas \\
\hline & 18 & 80211 & Controlo público da Tecnologia \\
\hline $\begin{array}{l}\text { Natureza do } \\
\text { conhecimento } \\
\text { científico }\end{array}$ & 19 & 90211 & Natureza dos modelos científicos \\
\hline
\end{tabular}

Fonte: Canavarro (2000).

Cada item é composto por uma afirmação inicial, seguida por diversas opções de resposta que representam os pontos de vista/conceções dos inquiridos sobre tópicos CTS. Nesta versão do questionário VOSTS, é também proposto um esquema de classificação das opções de resposta por três categorias: (i) realista - uma escolha que expressa uma conceção apropriada da Ciência, consentânea com as atuais visões do empreendimento científico; (ii) aceitável - uma escolha parcialmente legítima, mas não totalmente adequada, isto é, coerente com os conhecimentos de história, epistemologia e sociologia da 
ciência e (iii) ingénua - uma escolha inapropriada. As três últimas opções de resposta ("Não compreendo", "Não tenho conhecimentos para fazer uma escolha" e "Nenhuma das afirmações anteriores coincide com o meu ponto de vista"), que surgem sempre em todas as afirmações, são classificadas dentro da categoria ingénua.

As entrevistas individuais semiestruturadas foram realizadas para aprofundar as conceções CTS das futuras professoras expressadas no questionário VOSTS, particularmente as classificadas como ingénuas. Nas entrevistas, audiogravadas e transcritas na sua totalidade, as futuras professoras tiveram a oportunidade de descreverem os seus pontos de vista e de explicitarem as opções que tomaram no questionário. As transcrições das entrevistas foram devolvidas às futuras professoras para sua validação. A sua análise recorreu ao mesmo sistema categorial do VOSTS e foi validada por um "perito" da área da Didática das Ciências.

Os dados e informações, apresentados neste estudo, foram voluntariamente fornecidos pelos participantes, perante confidencialidade e anonimato previamente garantidos no termo de consentimento livre e informado assinado pelos mesmos.

Este estudo assumiu, portanto, uma natureza qualitativa, uma vez que se pretendeu descrever, compreender e interpretar situações concretas (COUTINHO, 2014). Neste sentido, a análise de conteúdo foi a técnica privilegiada no tratamento dos dados recolhidos, uma vez que, segundo Amado (2014), além de permitir uma rigorosa e objetiva representação dos conteúdos através da sua codificação e classificação por categorias, permite o avanço no sentido de captação do seu sentido pleno. No caso da análise das entrevistas individuais semiestruturadas, solicitou-se a um "perito" em Didática das Ciências que validasse a sua categorização, já que "'é importante que a análise seja válida, isto é, fiel aos conteúdos a serem analisados (...) que as categorias elaboradas (...) traduzam o verdadeiro sentido dos dados (AMADO, 2014, p.339).

\section{Resultados}

A apresentação dos resultados relativos às conceções sobre CTS de cada futura professora será realizada tendo em conta os dois momentos de aplicação do questionário VOSTS e da realização das entrevistas individuais semiestruturadas, no início e no final da intervenção na UC de DCN.

\section{Início da Intervenção na Unidade Curricular de Didáticas das Ciências Naturais}

\section{Futura professora A}

Esta futura professora evidenciou, no levantamento inicial, cinco respostas realistas, seis aceitáveis e oito ingénuas. As conceções ingénuas evidenciadas no questionário VOSTS, foram exploradas na entrevista cujos episódios se apresentam sintetizados de seguida.

No que diz respeito à "Definição de Tecnologia" (item 2), a futura professora A (FPA) optou pela opção de resposta "Nenhuma das afirmações anteriores coincide com o meu ponto de vista”. Convidada a explicitar esta sua opção, foi possível constatar que a conceção se classifica como ingénua. Por um lado, considera, aceitavelmente, que a Tecnologia "é um conjunto de novos processos, instrumentos, máquinas" e "uma técnica de resolução de problemas". Contudo, por outo lado, revela que "se não tivesse o objetivo 
de pretender fazer algo a tecnologia não servia para nada ou servia apenas para as novas tecnologias" (FP23), acrescentando que esse objetivo "é o de servir a ciência, ser uma aplicação da ciência" (FP25). Estas respostas indiciam que a FP revela uma conceção ingénua de Tecnologia.

$\mathrm{Na}$ resposta ingénua seguinte, correspondente ao tópico "Ciência e Tecnologia e qualidade de vida", a FPA defendeu, no questionário, que o investimento quer na Ciência, quer na Tecnologia se justifica "porque cada uma beneficia a sociedade à sua maneira. Por exemplo, a ciência dá-nos avanços médicos e a tecnologia traz consigo maior eficiência". $\mathrm{Na}$ entrevista, após nova leitura do item e das respetivas opções de resposta, volta a escolher esta mesma opção, acrescentando o documentado no seguinte episódio:

E30 - e porque é que achas que se justifica o investimento tanto na ciência como na tecnologia? porque é que achas que é importante esse investimento?

FP30 - para podermos evoluir de modo geral e (...) lá está a saúde, é sempre um exemplo porque (...) se não tivesse havido ou se não continuasse a haver um investimento tanto na ciência como na tecnologia, possivelmente, não teríamos tantas curas para tantas doenças como (...) há uns anos não tínhamos.

E31 - e consegues dar um exemplo de um contributo da tecnologia por exemplo para esses avanços? ou mesmo da ciência?

FP31 - não sei, mas supostamente para (...) solucionar esses problemas é preciso (...) por exemplo investigação em laboratórios e depois a concretização (...) lá está em laboratórios é preciso a concretização (...) desse conhecimento

E32 - e a concretização é a tecnologia?

FP32 - sim (...) através de máquinas

Este episódio reforça a conceção ingénua de Tecnologia, manifestada pela FPA na resposta ao item apresentado anteriormente, encarada como a concretização da investigação científica "através de máquinas". Esta conceção aliada ao facto de considerar que o investimento na investigação científica e tecnológica se justifica "porque a Ciência dá-nos avanços médicos e a Tecnologia traz consigo maior eficiência", evidenciam uma visão que não é aproximada do atual empreendimento científico. Com efeito, não é evidente a conceção realista de Tecnologia como um conjunto de ideias e técnicas para a conceção de produtos, para a organização do trabalho das pessoas e para o progresso na sociedade, sendo sobretudo associada a instrumentos e artefactos técnicos.

As três conceções ingénuas seguintes, relacionadas com o "Controlo político e governamental da Ciência", o "Controlo da Ciência pelo setor privado" e com a "Influência de grupos de interesse particular sobre a Ciência", na entrevista, mantiveramse. Sobre o primeiro destes tópicos, a FPA considera que os cientistas são afetados pelas políticas dos seus países porque tentam compreender e auxiliar a sociedade, ainda assim, revela que "os cientistas fazem parte da sociedade" e, por isso, dependendo do seu país "têm permissão para explorar mais ou menos ou para lidar com determinados problemas ou não, consoante as políticas" (FP33), tendo esta perspetiva características aceitáveis. Nos outros dois tópicos, a FPA evidenciou, na entrevista, à semelhança do questionário, que não tem conhecimentos para justificar uma escolha, nomeadamente sobre a influência ou não, por parte de instituições ou grupos, nos projetos de investigação.

Já na questão relativa à necessidade de estabelecer compromissos entre efeitos positivos e negativos da Ciência e da Tecnologia, a FPA, na entrevista, coloca desde logo de parte a opção que tomou no questionário e revela uma conceção aceitável relativamente a este tópico, defendendo que poderão existir ou não compromissos entre os efeitos positivos e negativos da Ciência e da Tecnologia, uma vez que "os efeitos negativos não 
podem ser totalmente eliminados" (FP41), quanto muito minimizados através de um "planeamento sério e rigoroso" (FP42; FP50).

No item 14, sobre o tópico "Vida social dos cientistas", a FPA parece continuar a indicar uma conceção predominantemente ingénua, já que defende que "sendo profissionais [os cientistas] têm que se focar na sua profissão, naquilo que lhes é incutido e naquilo que estão a fazer" (FP66). É, portanto, verosímil inferir que a FPA possui uma visão idealista de cientista quanto à sua vida social, como alguém que necessita de um grande envolvimento no seu trabalho de forma a garantir o sucesso.

$\mathrm{Na}$ última questão, sobre a "Natureza dos modelos científicos" (item 19), na entrevista, foi possível inferir que a FPA possui uma conceção predominantemente aceitável, defendendo que os modelos científicos se aproximam da realidade e que "à medida que a ciência vai avançando [...] é possível ficarem mais realistas mas não sei se já chegámos a esse ponto" (FP69).

\section{Futura professora $B$}

A futura professora B (FPB) evidenciou dez respostas realistas, quatro aceitáveis e cinco ingénuas. Destas, à exceção das respostas aos itens 7 e 13, sobre os tópicos "Influência de grupos de interesse particular sobre a Ciência" e "Ideologias e crenças religiosas dos cientistas", respetivamente, as restantes três tiveram como opção de resposta "Nenhuma das afirmações anteriores coincide com o meu ponto de vista".

$\mathrm{Na}$ entrevista, convidada a explicitar o seu ponto de vista sobre o item 7 , foi possível perceber que a conceção da FPB foi classificada como ingénua, uma vez que considera que os cientistas não recorrem a influências para obterem fundos para $o$ desenvolvimento do seu trabalho, acredita que estes podem ser totalmente autónomos (FP43; FP44) e que se apresentarem argumentos que fundamentem a pertinência das suas investigações, a política do país acaba por apoiar essas investigações (FP46; FP47). Defende, ainda, que os cientistas podem ser afetados pelas políticas dos seus países, contudo, há a possibilidade de um consenso entre ambos que permita aos cientistas levar avante as suas investigações (FP51; FP54). Além disso, revela que os cientistas investigam áreas que vão ao encontro das necessidades da sociedade, ou seja, que permitam compreender e auxiliar a sociedade (FP50; FP51). Não há, portanto, a visão/conceção de que os fundos financeiros para a Ciência provêm, sobretudo, do Governo e que, por vezes, os cientistas têm de recorrer a influências outras para obterem fundos para as suas investigações.

$\mathrm{Na}$ resposta ingénua seguinte, sobre o tópico "Influência de grupos de interesse particular sobre a Ciência", a FPB, na entrevista, após nova leitura do item e das opções de resposta, volta a escolher a mesma opção justificando:

FP57 - [...] mesmo que essas associações tenham os ideais perfeitos e acham que aquilo [que defendem] é o correto (...) acho que os cientistas também devem (...) se estes não concordarem (...) também devem mostrar provas em como aquilo não é assim tão bom ou tão favorável como eles [as associações ou grupos] estavam a dizer . acho que (...) deve haver sempre um consenso entre as duas partes e, . e só havendo um consenso é que vai ser o melhor para a sociedade

E58 - então a última palavra cabe aos cientistas ?

FP58 - sim porque eu assumi esta parte do "cabendo a última palavra aos cientistas" de modo a que eles . . . como são mais especializados em certas áreas não é (...) que eles expliquem (...) porque eu vejo muitas associações que até têm pessoas à frente da associação que não percebem nada daquilo e que não têm assim um conhecimento científico tão grande para dizer certas coisas que dizem (...) e os cientistas supostamente (...) não é (...) são pessoas mais 
especializadas (...) e (...) e (...) pessoas que têm muito mais conhecimento científico e acho que os dois juntos [associações e cientistas] conseguem uma melhor solução

E59 - então os cientistas tendo mais conhecimento científico (...) é por esse motivo que lhe acaba por caber a última palavra ?

FP59 - sim, sendo favorável ou não (...) porque eles têm argumentos que comprovam ou não aquilo que eles estão a dizer (...) mas claro (...) depois eu acho que nenhuma associação vai fazer alguma coisa que tenha provas que aquilo não vai resultar ou que aquilo não é bom (...) acho eu (...) acho que é um bocado por aí

Neste episódio, destacam-se três aspetos. O primeiro prende-se com o facto da FPB considerar que se pode chegar a um consenso entre as instituições ou grupos e os cientistas, caso haja fundamentos e provas que defendam as suas posições. O segundo aspeto, muito relacionado com o anterior, tem a ver com a ideia de que, pelo facto de os cientistas terem mais conhecimento científico e, consequentemente, conseguirem comprovar a pertinência das suas investigações, as instituições ou grupos não se vão opor às mesmas. $\mathrm{O}$ último aspeto relaciona-se com a visão de que a última palavra cabe sempre aos cientistas, sendo uma vez mais salientada a justificação de que estes têm mais conhecimento científico do que os membros ou representantes de instituições ou grupos. Estes aspetos evidenciam que a conceção da FPB relativamente a este tópico se mantém ingénua.

No item 12, a opção ingénua foi explorada durante a entrevista. Em primeiro lugar, do episódio relativo à exploração deste item, salienta-se que, apesar de alguma hesitação inicial, a conceção ingénua da FPB se mantém, uma vez que considera que "nem sempre mais tecnologia significa melhor nível de vida", salientando que "há muitas fábricas e muitas empresas que se calhar dão tanto valor à maquinaria que acabam por desprezar as pessoas" (FP60). Além disso, destaca que a Tecnologia pode não trazer uma vida mais fácil, sobretudo porque tem prejudicado as interações sociais (físicas) entre os indivíduos (FP61), defendendo que deve haver um equilíbrio na sua utilização por destes (FP64). Por outro lado, considera que a Tecnologia traz consigo poluição (FP62). O último aspeto que ressalta da exploração da opção de resposta ingénua a este item, prende-se com o facto de preconizar a Tecnologia como "invenções [...] tecnológicas ou seja informática, fábricas e esse tipo de maquinaria" (FP60).

Esta perspetiva revelada pela FPB evidencia, também, que apesar da resposta ao item 2 - definição de Tecnologia - ser realista, na entrevista, revela uma conceção ingénua, considerando a Tecnologia como meios e instrumentos técnicos.

Na resposta ingénua seguinte (item 13), sobre as ideologias e crenças religiosas dos cientistas, a FPB optou pela opção de resposta "As crenças religiosas não afetam o trabalho do cientista. As descobertas científicas são fundamentadas em teorias e em métodos experimentais. As crenças religiosas são exteriores à Ciência”. Convidada a explicitar, na entrevista, esta sua opção, obtiveram-se as interações documentadas no seguinte episódio:

FP70 - [...] eu acho que (...) apesar de terem aquela percentagem (...) que vai afetar (...) acho que essa percentagem afeta no sentido em como nós (...) desenvolvemos essa atividade e essa investigação (...) não é obrigatoriamente no produto final nem no (...) nem na conclusão final (...) acho que afeta no nosso (...) afeta-nos mais no nosso nível pessoal no sentido em que (...)

E71 - não vai afetar a investigação em si ? a investigação vai se manter igual e os resultados os mesmos?

FP71 - eu acho que sim (...) afeta é o nosso procedimento (...) acho que se calhar duas pessoas com religiões diferentes e com (...) e com valores diferentes (...) se calhar chegam ao mesmo resultado mas o procedimento em si é diferente (...) porque se calhar tomam decisões diferentes em prol (...) dos seu valores e das suas crenças (...) mas acho que se é fundamentado com argumentos e (...) em teorias acho que não (...) acho que nem sequer abrange (...) 
Deste episódio, é possível inferir que a FPB mantém uma conceção ingénua sobre as ideologias e crenças religiosas dos cientistas, possuindo uma visão do cientista como imune às ideologias e crenças religiosas. Ainda assim, admite que as crenças religiosas podem determinar a forma como o cientista seleciona a metodologia de investigação.

A última resposta ingénua é relativa à vida social dos cientistas (item 14), tendo a FPB, revelado, na entrevista, uma visão mais realista, considerando que depende de cada indivíduo; uns envolvem-se tão profundamente que se isolam da sociedade, enquanto outros conseguem conciliar a profissão com a sua vida familiar e social (FP76; FP78).

\section{Futura professora $C$}

Esta futura professora evidenciou nove respostas realistas, seis aceitáveis e quatro ingénuas.

No item 1, sobre o tópico "Definição de Ciência", a conceção da futura professora C (FPC) mantém-se ingénua. A FPC revela que é muito difícil definir Ciência, uma vez que essa definição será sempre incompleta (FP39; FP40). Além disso, preconiza a Ciência como um conjunto de "áreas que se juntam para um determinado objetivo" (FP44). Revela, portanto, uma conceção de Ciência não consentânea com visões contemporâneas do empreendimento científico.

$\mathrm{Na}$ seguinte resposta ingénua, correspondente ao tópico "Influência de grupos de interesse particular sobre Ciência", a FPC assumiu, no questionário, não ter conhecimentos para fazer uma escolha. Na entrevista, começou por hesitar e continuou a considerar não estar muito por dentro do assunto (FP45; FP46), ainda assim, convidada a explicitar o que pensa e a ler novamente as opções de respostas, obtiveram-se as interações documentadas no episódio seguinte:

FP48 - [...] nesse caso (...) acho que ou respondia a $F(.$.$) e aqui (...) e a C$ (..) não achando que por influenciarem a opinião pública influenciam os cientistas mas no sentido de a opinião pública ter muita influência (...) não sobre o cientista ou sobre o que o cientista acha (...) mas sobre o que o rodeia que o leva a fazer alguma coisa (...) ou seja por exemplo a opinião pública pode influenciar os apoios que o cientista tem para fazer alguma coisa (...) e não influenciar o cientista (...) mas o cientista sem esses apoios já não consegue fazer nada (...) acho que é por aí E49 - então optavas pela $\mathrm{C}$ agora não é ? [lê a opção de resposta $\mathrm{C}$ do item 7 do questionário VOSTS] "porque influenciam a opinião pública e por conseguinte os cientistas" (...) nesse sentido que estava a explicar. ou a $\mathrm{F}$ é isso ? [lê a opção de resposta $\mathrm{F}$ do item 7 do questionário VOSTS] "embora tentem nem sempre estas instituições ou grupos conseguem influenciar com êxito a condução de determinadas pesquisas, cabendo a última palavra aos cientistas"

FP49 - sim é isso

E50 - mas são perspetivas diferentes porque aqui cabe a última palavra aos cientistas e aqui os cientistas sem apoio não conseguem investigar

FP50 - sim são diferentes (...) por isso é que eu mudei um pouco esta [aponta para a opção de resposta $\mathrm{C}$ do item 7 do questionário VOSTS] (...) porque depende também das situações (...) acho eu (...) não sei

E51 - achas que cabe a última palavra aos cientistas ou não ?

FP51 - sem apoio [os cientistas] não conseguem fazer muito (...) mas acho que sim

E52 - mas se quiserem levar a sua investigação avante podem levar sem o apoio é isso ?

FP52 - sim (...) acho eu (...) não percebo muito do assunto.

Deste episódio, destacam-se dois aspetos. O primeiro prende-se com o facto da FPC considerar que a opinião pública não influencia necessariamente os cientistas, mas sim a opinião de que lhes dá os apoios para desenvolverem as suas investigações. $\mathrm{O}$ segundo relaciona-se com a manifestação de alguma incoerência de perspetiva 
relativamente ao facto de os cientistas puderem conduzir as suas investigações com ou sem apoio. Estes aspetos evidenciam que a FPC alterou a sua resposta para uma conceção igualmente e ingénua, embora algumas com características aceitáveis.

$\mathrm{Na}$ resposta ao tópico "Ideologias e crenças religiosas dos cientistas", na entrevista, a conceção ingénua da FPC manteve-se. A participante apresentou razões como: (i) "as crenças religiosas não entram na minha vida" (FP52); (ii) "eu acho que as crenças religiosas não devem entrar no trabalho do cientista (FP52)"; e (iii) "se é um cientista tem que trabalhar em prol da humanidade, portanto as crenças religiosas obviamente não devem entrar" (FP56). Estas razões indicam que a FPC parte da sua experiência pessoal, afirmando que as crenças religiosas não afetam o seu trabalho. Consequentemente, estabelece uma diferença entre o "ser" e o "dever", considerando que as crenças religiosas não devem afetar o trabalho dos cientistas. É possível inferir que a FPC possui uma visão idealista de cientista que parece ser imune às ideologias e crenças religiosas, bem como, tal como se constatou no item anterior, à influência de grupos de interesse particular sobre a Ciência.

No item 16, sobre a "Tomada de decisão sobre questões de Ciência", FPC optou pela resposta "Nenhuma das afirmações anteriores coincide com o meu ponto de vista". Na entrevista, mudou de perspetiva, pois passou a preferir a opção de resposta que preconiza que os cientistas podem não conseguir encontrar um consenso acerca de um assunto "por diversas razões" (FP72), nomeadamente "falta de factos, desinformação, teorias diferentes, opiniões pessoais, valores morais ou motivos individuais". Ora, tendo como referência o esquema de classificação das respostas do VOSTS, esta resposta é classificada como realista.

\section{Final da Unidade Curricular de Didática das Ciências Naturais}

\section{Futura professora A}

No final da UC de DCN, classificamos sete respostas realistas, sete aceitáveis e cinco ingénuas, no questionário da FPA. Estas últimas respostas correspondem, respetivamente, aos tópicos: "Ciência e Tecnologia e qualidade de vida", "Controlo da Ciência pelo setor privado", "Influência de grupos de interesse particular sobre a Ciência", "Contribuição da Ciência e da Tecnologia para o bem-estar económico" e "Controlo público da Tecnologia".

Em termos comparativos, verifica-se que, após a formação proporcionada na UC de DCN, o número de respostas realistas e aceitáveis aumentou e, consequentemente, diminuiu o número de respostas ingénuas: de oito (no questionário) e seis (na entrevista) para cinco (no questionário) e três (na entrevista). Nestas, excetuando os itens sobre os tópicos "Contribuição da Ciência e da Tecnologia para o bem-estar económico" (item 12) e "Controlo público da Tecnologia" (item 18), que evoluíram para conceções realistas e aceitáveis, respetivamente, todas as outras são referentes aos mesmos itens, continuando a concordar com as opções tomadas no questionário.

\section{Futura professora $B$}

A FPB, no final da formação na UC de DCN, indicou dez respostas realistas, seis aceitáveis e três ingénuas. Estas últimas correspondem, respetivamente, aos tópicos "Influência de grupos de interesse particular sobre a Ciência", "Contribuição da Ciência e 
da Tecnologia para a resolução de problemas sociais" e "Tomada de decisão sobre questões científicas".

Em termos comparativos, verifica-se que, entre o início e o final da UC de DCN, o número de respostas realistas manteve-se; contudo, aumentou o número de respostas aceitáveis, tendo o número de respostas ingénuas diminuído de cinco (no questionário) e quatro (na entrevista) para três (no questionário) e duas (na entrevista). Nestas, apenas uma é referente ao mesmo item sobre o tópico "Influência de grupos de interesse particular sobre a Ciência".

$\mathrm{Na}$ resposta ingénua ao tópico "Contribuição da Ciência e da Tecnologia para a resolução de problemas sociais", a FPC considerou, no questionário, não ter conhecimento para fazer uma escolha. $\mathrm{Na}$ entrevista, revelou que a comunidade tem que "saber usufruir [...] da nova tecnologia e [...] do avanço da Ciência" (FP20), acrescentando ainda que "de todo que não origina outros, se calhar sim para algumas populações que não sabem usufruir corretamente dessa evolução [da Ciência e da Tecnologia]" (FP20). Considera, portanto, que a contribuição da Ciência e da Tecnologia para a resolução de problemas se prende com a utilização correta das mesmas por parte das pessoas, sendo esta conceção aceitável. Ainda assim, esta conceção regrediu uma vez que, no levantamento inicial, a FPB manifestou, no questionário, uma conceção realista. Também no tópico "Tomada de decisão sobre questões científicas" regrediu de realista para ingénua. De facto, a FPC, na entrevista, revelou que os cientistas interpretam factos de modo diverso, à luz de diferentes teorias científicas e, por isso, não conseguem encontrar um consenso sobre um assunto (FP22; FP23).

\section{Futura professora $C$}

No final da intervenção na UC de DCN, classificamos as respostas da FPC como: doze respostas realistas, quatro aceitáveis e três ingénuas. Estas últimas correspondem, respetivamente, aos tópicos: "Ciência e Tecnologia e qualidade de vida" (item 3), "Contribuição da Ciência e da Tecnologia para a criação de problemas sociais" (item 11) e "Vida social dos cientistas" (item 14).

Em termos comparativos, percebe-se que, entre o início e o final da UC de DCN, o número de respostas realistas aumentou de nove (no questionário) e dez (na entrevista) para doze (no questionário) e treze (na entrevista); o número de respostas aceitáveis diminuiu de seis (no questionário e entrevista), para cinco (na entrevista), assim como o número de resposta ingénuas, de quatro (no questionário) e três (na entrevista), para três (no questionário) e duas (na entrevista). Nesta última, sobre o tópico "Contribuição da Ciência e da Tecnologia para a criação de problemas sociais", a conceção regride de aceitável (no levantamento inicial) para ingénua (no levantamento final), uma vez que defendeu, na entrevista, que nem sempre existirão compromissos entre os efeitos positivos e negativos da Ciência e da Tecnologia "porque certos novos desenvolvimentos beneficiam a humanidade sem causar efeitos negativos". Também no item 14 , a conceção regride mas, desta vez, de realista para predominantemente ingénua, com algumas características aceitáveis. A FPC considera que os cientistas se comportam de modo diferente "porque têm outras obrigações para levar o seu estudo para a frente" (FP20); contudo revela "isso não significa que não tenham vida familiar ou social" (FP20).

\section{Síntese global e discussão dos resultados}


A análise dos dados apresentados, anteriormente, permite fazer emergir as categorias de resposta sobre as conceções acerca da Ciência, numa perspetiva de interligação com a Tecnologia e a Sociedade, partilhadas por mais do que uma das futuras professoras, nos dois momentos em que se procedeu ao seu levantamento: no início e no final da UC de DCN (Quadro 2). Esse quadro indica as opções de resposta das professoras para cada item do questionário.

Quadro 2 - Conceções manifestadas pelas futuras professoras no início e no final da intervenção na UC de $\mathrm{DCN}$

\begin{tabular}{l|c|c|c|c}
\cline { 2 - 5 } \multicolumn{2}{c|}{ Início da UC de DCN } & \multicolumn{2}{c}{ Final da UC de DCN } \\
\hline Conceções & Questionário VOSTS & Entrevista & Questionário VOSTS & Entrevista \\
\hline Realista & 23 & 26 & 29 & 33 \\
\hline Aceitável & 16 & 18 & 17 & 17 \\
\hline Ingénua & 17 & 13 & 11 & 7 \\
\hline
\end{tabular}

Fonte: Elaborado pelos autores.

Do quadro acima, constata-se que, na totalidade dos itens, quer no levantamento inicial, quer no final, as três futuras professoras expressaram, maioritariamente, considerando o esquema de classificação das respostas do VOSTS, conceções realistas e aceitáveis. Ainda assim, no início da UC de DCN, prevalecia um número mais elevado de conceções ingénuas, do que no final da UC. esquema de classificação das opções de resposta por três categorias:

A análise de conteúdo das entrevistas individuais semiestruturadas permitiu verificar que, de acordo com o esquema de classificação das opções de resposta proposto por Canvarro (2000), no início da UC, predominavam conceções ingénuas do tipo:

(i) Tecnologia como aplicação da Ciência e como um conjunto meios e instrumentos técnicos;

(ii) a política do país não afeta o trabalho dos cientistas;

(iii) não existe influência de grupos de interesse particulares sobre a Ciência;

(iv) as ideologias e crenças religiosas dos cientistas não afetam o seu trabalho;

As futuras professoras A e B possuíam um maior número de conceções ingénuas (6 e 5, respetivamente) do que a futura professora $\mathrm{C}$ (3). Além do maior número de conceções ingénuas, as futuras professoras A e B, no início da intervenção, parecem partilhar da mesma perspetiva instrumental da Tecnologia que está subordinada à Ciência e que não é mais do que a sua aplicação no quotidiano. Esta conceção, que coloca a Tecnologia num plano subsidiário à Ciência, foi também encontrada em outros estudos, levados a cabo com futuros professores de Ciências, nomeadamente o de Yalvac et al. (2007).

O mesmo acontece com o tópico "Controlo político e governamental da Ciência", relativamente ao qual as futuras professoras A e B parecem evidenciar um desconhecimento da influência sociopolítica a que o cientista está sujeito, conforme ilustra o raciocínio da futura professora B: "eu acho que se eles [os cientistas] apresentarem . uma investigação e fundamentos . que validem mais a sua perspetiva (...) acho que o governo até pensa e apoia" (FP46; FP47). Já sobre o tópico "Ideologias e crenças religiosas dos cientistas", a conceção ingénua é partilhada pelas futuras professoras B e C, uma vez que 
parecem revelar no seu discurso uma diferença entre o "ser" e o "dever", considerando que o cientista não se deve deixar afetar. O cientista é, portanto, visto por um prisma idealista, como alguém que parece ser imune às crenças religiosas. Por outro lado, as três futuras professoras parecem partilhar da mesma perspetiva ingénua relativamente ao tópico "Influência de grupos de interesse particular sobre a Ciência", evidenciando no seu discurso que não existe influência porque "a última palavra cabe aos cientistas".

Estas conceções sustentam um perfil global às três futuras professoras no início da UC: um realismo ingénuo e um desconhecimento das complexas interações entre a Ciência, a Tecnologia e a Sociedade. Tal quadro de conceções é consonante com as obtidas em outros estudos com futuros professores de Ciências, nos quais estes mostraram conceber as teorias científicas acima das políticas, ideologias, crenças religiosas, valores morais ou motivações pessoais (AMIRSHOKOOHI, 2010; DIKMENTEPE; YAKAR, 2016, YALVAC et al., 2007). Pode, portanto, considerar-se que tais conceções não estão ancoradas numa reflexão prévia das implicações sociais da Ciência e da Tecnologia (VIEIRA; MARTINS, 2005).

Após a intervenção na UC de DCN, as futuras professoras A e B mantiveram a conceção ingénua do tipo: não existência de influência de grupos de interesses particulares sobre a Ciência. Esta inconsistência poderá estar relacionada com o facto de este tópico em específico não ter sido explicitamente focado no decorrer da intervenção na UC de DCN. Além disso, as futuras professoras $\mathrm{B}$ e $\mathrm{C}$ manifestaram uma regressão das conceções de realista e aceitável, respetivamente, para ingénua no tópico "Contribuição da Ciência e da Tecnologia para a resolução de problemas sociais". Esta inconsistência poderá estar relacionada com dois aspetos: (i) com o facto das conceções realistas e aceitáveis não serem exploradas em entrevista, o que poderá significar que, apesar de no levantamento inicial a FPB ter, no questionário, optado por uma resposta realista, a sua conceção ser efetivamente aceitável ou ingénua ou (ii) com o facto de este tópico em específico não ter sido explicitamente focado no decorrer da UC de DCN. Estes aspetos poderão estar igualmente no cerne da regressão das conceções realistas para ingénuas das professoras B e C nos tópicos "Tomada de decisão sobre questões científicas" e "Vida social dos cientistas", respetivamente.

Ainda assim, em termos comparativos e tal como se pode constatar no quadro 2, houve um aumento do número de respostas consideradas realistas e uma diminuição significativa do número de respostas ingénuas. De um modo geral, no final da UC de DCN, apesar de persistirem conceções CTS ingénuas, considerou-se a evolução para uma imagem mais contextualizada da Ciência.

\section{CONSIDERAÇÕES FINAIS}

Tendo por referência a finalidade do presente estudo, os seus resultados sugerem que a intervenção realizada na Unidade Curricular de Didática das Ciências Naturais contribuiu para a (re)construção das conceções das três futuras professoras envolvidas. Essas conceções evoluíram para visões mais realistas da Ciência e das suas inter-relações com a Tecnologia e a Sociedade. Esta conclusão decorre, essencialmente, da análise comparativa entre as conceções reveladas pelas futuras professoras no início e no final da Unidade Curricular e das evidências incluídas nos resultados, considerando a evolução do número de respostas consideradas realistas e a consequente diminuição do número de 
respostas ingénuas. Importa, contudo, ressalvar que, por um lado, estas constatações são inferências, pelo que se reconhecem algumas fragilidades dos instrumentos de recolha de dados utilizados, essencialmente no que concerne ao risco de interferência do investigador nas respostas dos participantes (no questionário e na entrevista). Por outro lado, existem outros fatores, nomeadamente outras experiências vivenciadas pelas futuras professoras fora do contexto da UC onde decorreu este estudo, que poderão ter interferido nos resultados apresentados.

Levando em conta que os professores influenciam as conceções dos seus alunos (MARQUES; COSTA, 2017; PEDERSEN; ISOZAKE; HIDRANO, 2017), pode considerar-se que as três futuras professoras, envolvidas na UC de DCN, poderão vir a influenciar positivamente as visões dos seus alunos sobre as interações CTS. De facto, só quando as conceções dos professores estão alinhadas com uma orientação CTS mais ampla para o ensino das Ciências é que os mesmos conseguem desenvolver práticas didáticopedagógicas menos ingênuas nesse sentido (ACEVEDO-DÍAZ, 2006; AMIRSHOKOOHI, 2010). Assim, além de se apresentarem e discutirem práticas didático-pedagógicas relevantes que explorem as interações recíprocas que se estabelecem entre a Ciência, a Tecnologia e a Sociedade, é preciso adotá-las na formação inicial de professores (NATIONAL RESEARCH COUNCIL, 2009).

Em síntese, ressaltam duas grandes implicações deste estudo. A primeira aponta para a necessidade de se encontrarem estratégias para que a formação inicial de professores (de Ciências) contribua, de forma efetiva, para ajudar os futuros professores a ultrapassar conceções de Ciência desadequadas e à margem das suas inter-relações com a Tecnologia e a Sociedade. A segunda implicação, que decorre intrinsecamente da primeira, prende-se com o facto da formação inicial de professores (de Ciências) constituir um dos elementos decisivos para que os futuros professores adotem práticas didático-pedagógicas que contribuam para melhorar os índices de alfabetização científica, fomentando $o$ desenvolvimento de conceções adequadas e de atitudes positivas face à Ciência. Assumese, portanto, premente manter um debate sobre a formação inicial de professores, uma vez que a melhoria da qualidade do ensino nas escolas e, consequentemente, da aprendizagem e do desempenho dos alunos está, também, fortemente condicionada pelas práticas didático-pedagógica dos seus professores.

\section{REFERÊNCIAS}

ACEVEDO DÍAZ, José Antonio. Modelos de relaciones entre ciencia y tecnología: un análisis social e histórico. Revista Eureka sobre Enseñanza y Divulgación de las Ciencias, v. 3, n. 2, 198-219, 2006.2 Disponível em: https://www.redalyc.org/articulo.oa?id=92030203

AIKENHEAD, Glen. S.; RYAN, Alan. G.; FLEMING, Reg. W. Views on sciencetechnology-society. Department of Curriculum Studies, College of Education: Saskatchewan, $1989 . \quad$ Disponível em: http://www.pearweb.org/atis/data/documents/000/000/002/vosts_2_.pdf

AMADO, João. Manual de Investigação Qualitativa em Educação (2. ${ }^{a}$ ed.). Coimbra: Imprensa da Universidade de Coimbra, 2014.

AMIRSHOKOOHI, Aidin. Elementary Pre-Service Teachers' Environmental Literacy and Views toward Science, Technology, and Society (STS) Issues. Science Educator, v. 19, n. 1, p. 56-63, 2010. Disponível em: https://files.eric.ed.gov/fulltext/EJ874154.pdf 
ANDERSON, Dayle. The nature and influence of teacher beliefs and knowledge on the science teaching practice of three generalist New Zealand primary teachers. Research in Science Education, v. 45, n. 3, p. 395-423, 2015. Disponível em: https://link.springer.com/article/10.1007/s11165-014-9428-8

BUEHL, Michelle. M.; BECK, Jori. S. The relationship between teachers' beliefs and teachers' practices. In H. Fives \& M. Gil (Eds.). International Handbook of Research on Teachers'Beliefs. New York, NY: Routledge, 2015. p. 66-84.

COUTINHO, Clara. Metodologias de Investigação em Ciências Sociais e Humanas: teoria e prática. Coimbra: Edições Almedina, 2014

DIKMENTEPE, Emel; YAKAR, Zeha. Preservice Science Teachers' Views on ScienceTechnology-Society. International Journal of Higher Education, v. 5, n. 2, p. 183-195, 2016. Disponível em: http://www.sciedu.ca/journal/index.php/ijhe/article/view/9054/5595

EURYDICE. $O$ ensino das ciências na Europa: Políticas nacionais, práticas $e$ investigações. Bruxelas: Agência de Execução relativa à Educação, ao Audiovisual e à Cultura (EACEA), 2012. Disponível em: http://www.dgeec.mec.pt/np4/np4/\%7B \$clientServletPath\%7D/?newsId=192\&fileName=e nsino_ciencias_europa_2012.pdf

JARVIS, Tina; RENNIE, Léonine J. Helping Primary Children Understand Science and Technology: Practical, Oral and Co-operative Activities. Leicester: SCIcentre, 2000.

MANSOUR, Nasser. Consistencies and Inconsistencies Between Science Teachers' Beliefs and Practices. International Journal of Science Education International Journal of Science Education, v. 35, n. 7, p. 1-47, 2013.

MARQUES, Luís; COSTA, Nilza. Science Teacher Education in Portugal. In PEDERSEN, Jon E.; ISOZAKE, Tetsuo; HIDRANO, Toshihde. (Eds.). Model Science Teacher Preparation Programs: An International Comparsion of What Works. Charlotte: Information Age Publishing, INC., 2017. p. 93-128.

MINISTÉRIO DA EDUCAÇÃO. Perfil dos alunos à saída da escolaridade obrigatória, 2017.

Disponível em: http://dge.mec.pt/sites/default/files/Curriculo/Projeto_Autonomia_e_Flexibilidade/perf il_dos_alunos.pdf

MINISTÉRIO DA EDUCAÇÃO (2018). Aprendizagens Essenciais - Ciência Naturais, 5. ${ }^{o}$ ano, 2018 Disponível em: http://www.dge.mec.pt/sites/default/files/Curriculo/Aprendizagens_Essenciais/2_ciclo/5_ci encias_naturais.pdf

MINISTÉRIO DA EDUCAÇÃO. Aprendizagens Essenciais - Ciência Naturais, $6 .^{\circ}$ ano, $2018 . \quad$ Disponível em: http://www.dge.mec.pt/sites/default/files/Curriculo/Aprendizagens_Essenciais/2_ciclo/6_ci encias_naturais.pdf

NATIONAL RESEARCH COUNCIL. A survey of attitudes and actions on dual use research in the life sciences: A collaborative effort of the National Research Council and the American Association for the Advancement of Science. National Academies Press, 2009. Disponível em: https://www.ncbi.nlm.nih.gov/books/NBK214757/ 
NATIONAL SCIENCE BOARD. Science \& Engineering Indicators 2014. Arlington VA: NSF, 2014. Disponível em: https://www.nsf.gov/statistics/seind14/content/etc/nsb1401.pdf NÓVOA, António. Pedagogia: a terceira margem do rio. In: Conferência Que Currículo para o Século XXI?. Lisboa: Assembleia da República, 2011. p. 39-46. Disponível em: http://www.cnedu.pt/content/antigo/files/pub/CurrSecXXI/CurrSecXXI6.pdf

PEDERSEN, Jon E.; ISOZAKE, Tetsuo; HIDRANO, Toshihde. Model Sience Teacher Pareparation Programs: An International Comparsion of What Works. Charlotte, NC: Information Age Publishing, 2017. p. 93-128.

DE PRO BUENO, Antonio. Qué Ciencias Deberíamos Enseñar en la Educación Obligaroria?. In: PEIXOTO, Ana; SÁ, César; OLIVEIRA, Joana; NEVES, Luísa; RAMALHO, Sandra. (Eds.). Livro de Resumos do XVII Encontro Nacional de Educação em Ciências, I Seminário Internacional de Educação em Ciências. Viana do Castelo: Escola Superior de Educação do Instituto Politécnico de Viana do Castelo, 2017. p. 13-14. Disponível em: http://www.ipvc.pt/sites/default/files/livro_resumos_2017_final_.pdf

DE PRO BUENO, Antonio. La construcción del conocimiento científico y los contenidos de ciências. In: Enseñar ciencias. Graó, 2003. p. 33-54.

RIGA, Fran; WINTERBOTTOM, Mark; HARRIS, Emily; NEWBY, Luke. Inquiry-based science education. In Science Education. Sense Publishers, 2017. p. 247-261.

RIVERO, Ana; MARTÍN DEL POZO, Rosa; SOLÍS, Emilio; AZCÁRATE, Pilar; PORLÁN, Rafael. Cambio del conocimiento sobre la enseñanza de las ciencias de futuros maestros. Enseñanza de las Ciencias, v. 35, n. 1, p. 29-52, 2017. Disponível em: https://www.raco.cat/index.php/Ensenanza/article/view/319567/409794

RODRIGUES, Ana V.; MARTINS, Isabel P. Formação inicial de professores para o ensino das ciências nos primeiros anos em Portugal. In: CACHAPUZ, António; NETO SHIGUNOV, Alexandre; FORTUNATO, Ivan (Org,). Formação inicial e continuada de professores de ciências: o que se pesquisa no Brasil, Portugal e Espanha. São Paulo: Edições Hipótese, 2018. p. 179 - $198 . \quad$ Disponível em: https://drive.google.com/file/d/1mvcTwFeXtyVmhZk_MKM72ziuBobA0KB2/view

TENREIRO-VIEIRA, Celina; VIEIRA, Rui M. Educação em Ciências e Matemática com Orientação CTS Promotora do Pensamento Crítico. Revista Iberoamericana de Ciencia, Tecnología y Sociedad, v. 11, n. 33, p. 143-159, 2016. Disponível em: http://www.revistacts.net/files/Volumen_11_Numero_33/FINALES/Vieira.pdf

VIEIRA, Rui M.; TENREIRO-VIEIRA, Celina. Práticas Didático-Pedagógicas de Ciências: Estratégias de Ensino/Aprendizagem promotoras do pensamento crítico. Revista Saber \& Educar, n. 20, p. 34-41, $2015 . \quad$ Disponível em: http://revista.esepf.pt/index.php/sabereducar/article/view/191/pdf_32

VIEIRA, Rui M.; MARTINS, Isabel P. Formação de professores principiantes do ensino básico: suas concepções sobre ciência-tecnologia-sociedade. CTS: Revista iberoamericana de ciencia, tecnología y sociedad, v.2, n. 6, p. 101-121, 2005. Disponível em: http://www.scielo.org.ar/pdf/cts/v2n6/v2n6a06.pdf

VIEIRA, Rui M.; TENREIRO-VIEIRA, Celina; MARTINS, Isabel P. A educação em ciências com orientação CTS: Atividades para o ensino básico. Lisboa: Areal Editores, 2011. 
WILKINS, Jesse. L. M. The relationship among elementary teachers' content knowledge, attitudes, beliefs, and practices. Journal of Mathematics Teacher Education, v. 11, n. 2, p. 139- 164, 2008. Disponível em: https://link.springer.com/article/10.1007/s10857-007$9068-2$

YALVAC, Bugrahan; TEKKAYA, Ceren; CAKIROGLU, Jale; KAHYAOGLU, Elvan. Turkish pre-service science teachers' views on science-technology-society issues. International Journal of Science Education, v. 29, n. 3, p. 331-348, 2007.

Recebido em: 18/11/2018

Aprovado em: 10/01/2019 